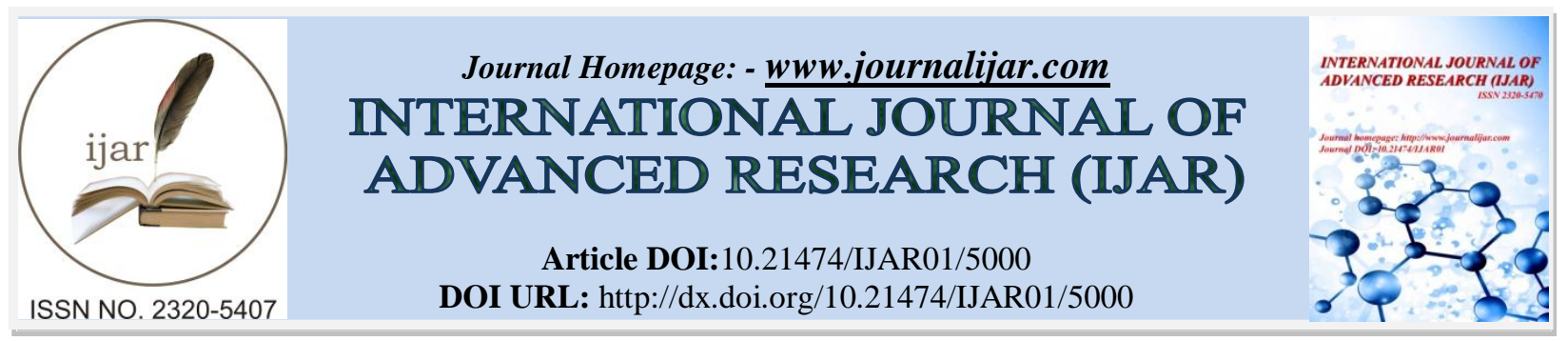

RESEARCH ARTICLE

\title{
REMOVAL OF DYES (METHYLENE BLUE, MALACHITE GREEN, METHYL VIOLET) ON ACTIVATED CARBON PREPARED FROM COPPER POD FLOWER.
}

\author{
N Saravanan ${ }^{1}$ and G Rathika ${ }^{2}$. \\ 1. Department of Chemistry, Nandha Engineering College, Erode- 638 052, Tamil nadu, India. \\ 2. Department of Chemistry, PSG College of Arts and Science, Coimbatore-641 014, Tamil nadu, India.
}

\section{Manuscript Info}

(..........................

Manuscript History

Received: 28 May 2017

Final Accepted: 30 June 2017

Published: July 2017

Key words:-

Copper pod flower, Methylene blue, Malachite green \& Methyl violet, Adsorption.

\section{Abstract}

This work was the study of adsorption behaviours of three dye solution (methylene blue, malachite green \& methyl violet) using commercial activated carbon prepared from copper pod flower. Removal of these three dyes from aqueous solution using commercial activated carbon has been investigated through batch experiment. The batch adsorption experiments were carried out by observing the effect of contact time, adsorbent dosage, $\mathrm{pH}$ and temperature. The results indicate that copper pod flower could be employed as a low cost alternative to commercial activated carbon for the removal of colour and dyes from aqueous solution.

Copy Right, IJAR, 2017,. All rights reserved.

\section{Introduction:-}

The effluents from textile industries are important sources of dye pollution. Many dyes and their products may be toxic for living organisms [1]. Decolourizations of dyes are important aspects of wastewater treatment before discharge. Waste water containing dyes are very difficult to remove, because of dyes are not easily degradable [2, 3]. They reduce light penetration and photosynthesis thus upsetting biological processes within a stream [4]. The presence of these dyes in industrial wastewater is of serious concern because they are highly toxic and carcinogen $[5,6]$. Several physical, chemical and biological methods have been suggested, developed and used to remove dyes from wastewater [7]. Among these methods, adsorption is a widely used for dye removal from wastewater. Activated carbon is the most common adsorbent for the removal of dyes from wastewater. This study was performed to utilize the copper pod flower as a low cost adsorbent with respect to various parameters such as different adsorbent dosages, contact time and $\mathrm{pH}$.

\section{Experimental work:-}

Materials and methods:-

\section{Adsorbent:-}

The present studies Copper Pod flowers were used as adsorbent for the removal malachite green dye from aqueous solution. They were collected from in around PSG College of Arts and Science, Coimbatore District, Tamilnadu, India which were available in abundant.

The copper pod flowers were washed thoroughly with ordinary tap water to remove any dust and twice with distilled water. The washed materials were dried in sun light to evaporate the moisture present in it. The dried materials were kept in muffle furnace. The carbonized material was ground to fine powder and then sieved with a particle size of 
$125 \mathrm{\mu m}$. The sieved adsorbent sample prepared was kept in an airtight container and used for further adsorption studies.

\section{Preparation of adsorbate:-}

In the present study three dyes (methylene blue, methyl violet \& malachite green) are used for the adsorption. A stock solution of $1000 \mathrm{ppm}$ of methylene blue, methyl violet \& malachite green was prepared by dissolving an appropriate amount of each dye which was diluted to required concentration. The working solutions were prepared by diluting the stock solution with distilled water to get the appropriate concentration of the working solutions. The concentration of the residual dye solution was measured using UV/Visible spectrometer at a $\lambda_{\max }$ value of $663 \mathrm{~nm}$ for methylene blue, $617 \mathrm{~nm}$ for malaghite green and 590nm for methyl violet.

\section{Adsorption Studies:-}

\section{Effect of contact time:-}

$50 \mathrm{ml}$ of dye solution with different dye concentration $\left(10-50 \mathrm{mg} . \mathrm{L}^{-1}\right)$ is to be prepared in a different $250 \mathrm{ml}$ conical flask with adsorbent concentration $(0.1 \mathrm{~g} / 50 \mathrm{ml})$. The conical flasks were well corked and the mixture was constantly shaken in a rotary shaker. Dye concentration to be estimated at the wavelength corresponding to maximum absorbance, $\lambda_{\max }$, using a spectrophotometer. The samples to be withdrawn from the orbital shaker at predetermined time intervals and then the absorbance of the solution is measured. The final dye concentration is to be measured after different time intervals (10 - 100mins) until equilibrium reaches.

\section{Effect of initial pH:-}

The effect of $\mathrm{pH}$ on the adsorption of methylene blue, malachite green and Methyl violet dyes onto copper pod flower was studied at a $\mathrm{pH}$ range of 2 to 10 in the presence of different initial dye concentrations $\left(10-50 \mathrm{mg} . \mathrm{L}^{-1}\right)$. $50 \mathrm{ml}$ of dye solution was prepared in a different conical flask with different dye concentration $\left(10-50 \mathrm{mg} . \mathrm{L}^{-1}\right)$ and adsorbent concentration $(0.1 \mathrm{~g} / 50 \mathrm{ml})$ and initial $\mathrm{pH}$ of the conical flask solution is to be measured. The $\mathrm{pH}$ of the dye solution was controlled by the addition of $0.1 \mathrm{M} \mathrm{HCl}$ or $0.1 \mathrm{M} \mathrm{NaOH}$ by using a $\mathrm{pH}$ meter. The final dye concentration was measured using UV spectrophotometer.

\section{Effect of adsorbent dose:-}

$50 \mathrm{ml}$ of dye solution was prepared in a different conical flask with different dye concentration $\left(10-50 \mathrm{mg} . \mathrm{L}^{-1}\right)$ and different adsorbent dosage of $0.1-1 \mathrm{~g}$. The conical flasks were well corked and the mixture was constantly shaken in a shaker for 60 minutes. The final dye concentration readings were measured after agitation.

\section{Effect of temperature:-}

$50 \mathrm{ml}$ of dye solution was prepared in conical flask with dye concentration (40 mg. $\left.\mathrm{L}^{-1}\right)$ and adsorbent dose $(0.1 \mathrm{~g} / 50 \mathrm{ml})$ and different temperatures of $30,40,45,50,55,60{ }^{0} \mathrm{C}$ for 60 minutes at a constant stirring speed.

\section{Results and discussion:- \\ Adsorption studies:- \\ Effect of contact time:-}

The effect of contact time on dye removal can be seen from Figure 1 to 3 . for the dyes. The result indicates that the extent of dye removal was faster in the initial stages of contact time and became constant when equilibrium was attained $[8,9]$. After that there is no significant change in the extent of adsorption. 


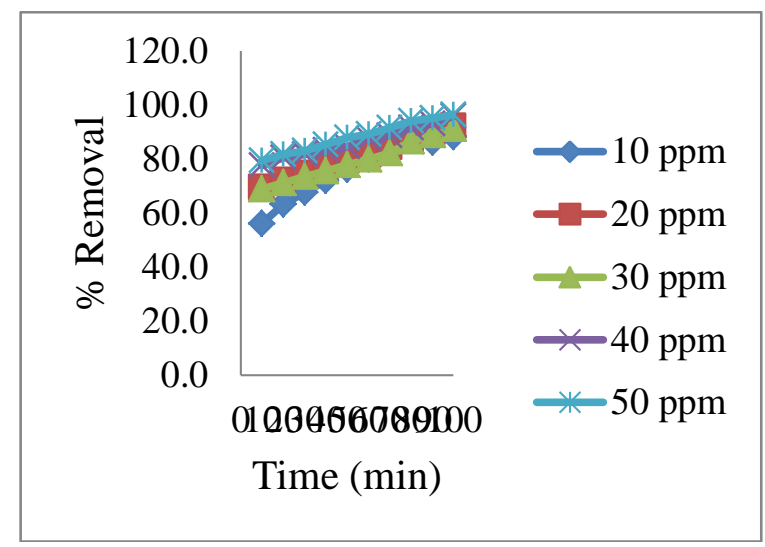

Figure 1:-Effect of contact Time on Methylene Blue adsorption on Activated carbon (initial dye concentration - (10 -50) $\mathrm{mg} / \mathrm{L}, \mathrm{pH}$-solution $\mathrm{pH}$, speed-120 rpm) and adsorbent dosage-100mg/50ml)

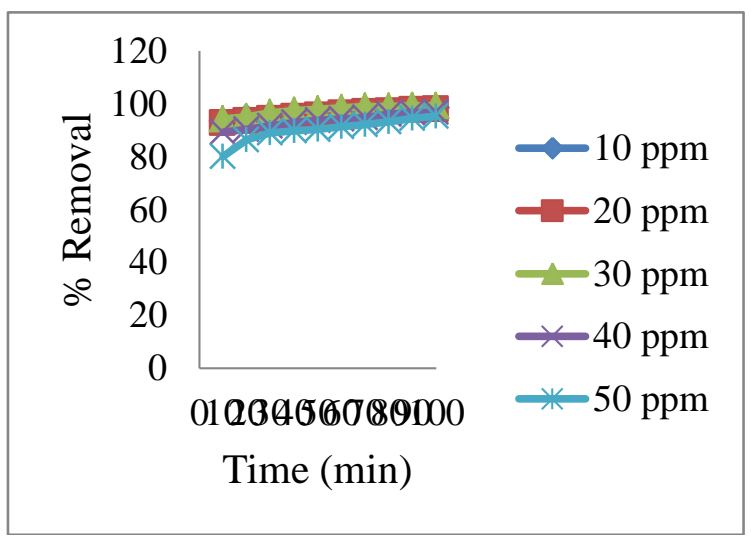

Figure 2:-Effect of contact Time on Malachite Green adsorption on Activated carbon (initial dye concentration $(10-50) \mathrm{mg} / \mathrm{L}, \mathrm{pH}$-solution $\mathrm{pH}$, speed-120 rpm) and adsorbent dosage-100mg/50ml)

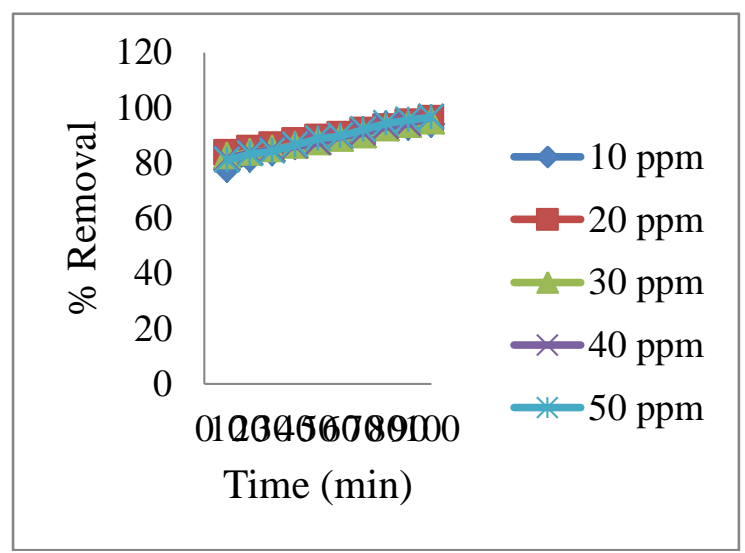

Figure 3:-Effect of contact Time on Methyl Violet adsorption on Activated carbon (initial dye concentration - (10 50) $\mathrm{mg} / \mathrm{L}, \mathrm{pH}$-solution $\mathrm{pH}$, speed-120 rpm) and adsorbent dosage- $100 \mathrm{mg} / 50 \mathrm{ml}$ )

\section{Effect of initial pH of the solution:-}

The $\mathrm{pH}$ of the solution is an important parameter for controlling the adsorption process. The effects of initial $\mathrm{pH}$ on dye solution of three dyes removal was illustrated in figure 4 to 6 . When the $\mathrm{pH}$ of dye solution increased from 2 to 12, the dye uptake was found to increase. From the figure, it is evident that adsorption found to increase with increase in $\mathrm{pH}$ of dye solution upto 7 and decreased gradually until $\mathrm{pH} 12$. From this study, it is observed that maximum dye adsorption takes place at $\mathrm{pH}$ 7. The increase in percentage of dye removal due to increase in $\mathrm{pH}$ may be explained on the basis of a decrease in competition between proton $\left(\mathrm{H}^{+}\right)$and positively charged dye at the surface 
sites $[10,11]$. When the $\mathrm{pH}$ value increased from $8-12$, there was a further decrease in the rate of adsorption by the adsorbent [12]. At high $\mathrm{pH}$, the adsorbent surface becomes positively charged and high concentration of $\mathrm{H}^{+}$ions which compete with cationic dye causing decrease in dye uptake.

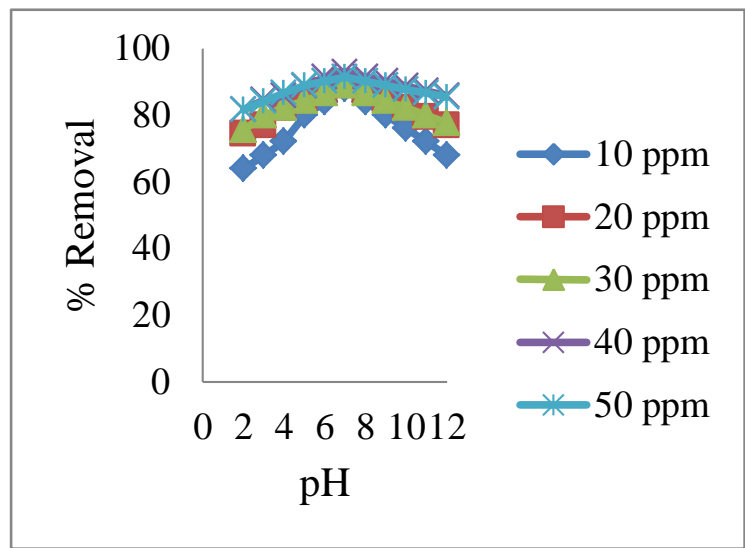

Figure 4:-Effect of Initial $\mathrm{pH}$ on Methylene Blue adsorption on Activated carbon (Temperature - room temperature, speed-120 rpm) and adsorbent dosage-100mg/50ml)

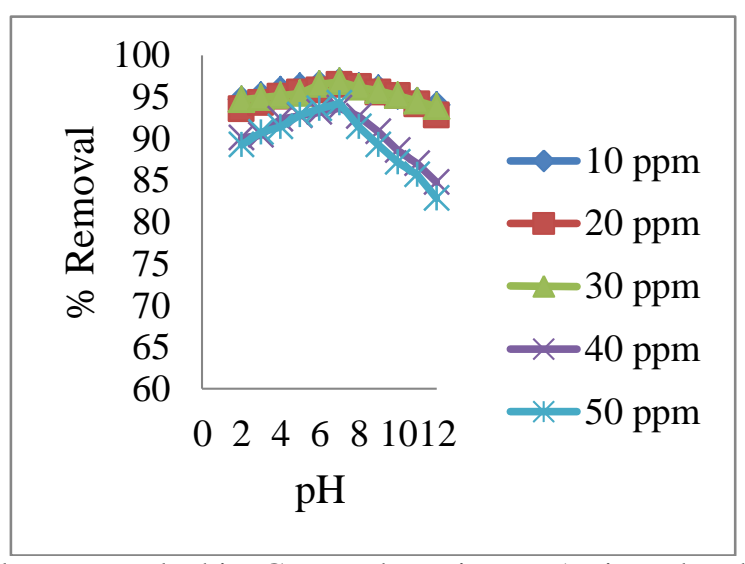

Figure 5:-Effect of Initial pH on Malaghite Green adsorption on Activated carbon (Temperature - room temperature, speed-120 rpm) and adsorbent dosage-100mg/50ml)

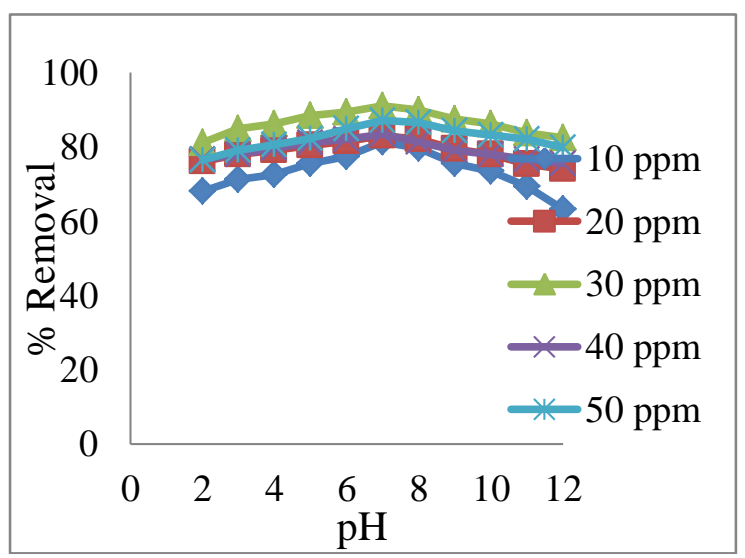

Figure 6:-Effect of Initial pH on Methyl violet adsorption on Activated carbon (Temperature - room temperature, speed-120 rpm) and adsorbent dosage-100mg/50ml) 


\section{Effect of adsorbent dosage:-}

The effects of adsorbent dosage on dye solution of three dyes removal was shown in figure 7 to 9 . The result shows that the percentage of dye removal increased with increase in adsorbent dosage. Initially the percentage of dye removal was found to be rapid which slowed down as the adsorbent dose increased [13]. The initial increase in adsorption with increase in amount of adsorbent dose is due to larger driving force and lesser surface area. The increase in the percentage removal of dyes with adsorbent dose due to the introduction of more binding sites for adsorption. The primary factor explaining this characteristic is that adsorption sites remain unsaturated during the adsorption reaction whereas the number of sites available for adsorption site increases by increasing the adsorbent dose $[14,15]$.

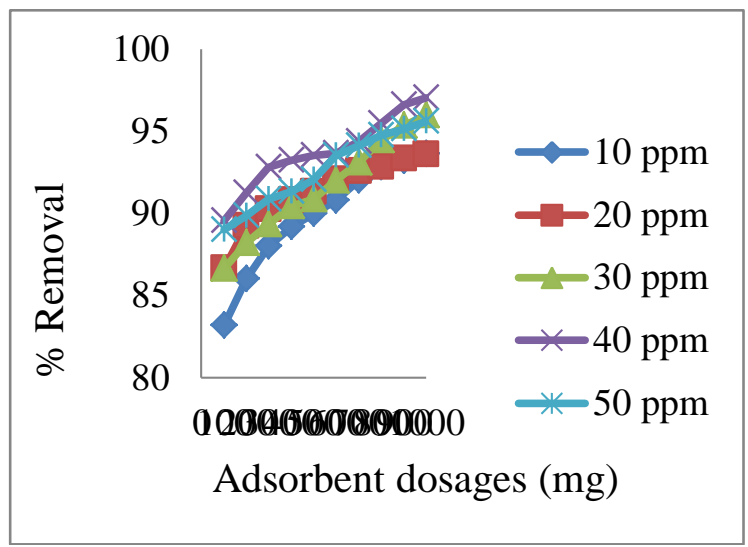

Figure 7:-Effect of adsorbent dosage on Methylene Blue adsorption on Activated carbon (Temperature - room temperature, $\mathrm{pH}$-solution $\mathrm{pH}$, speed-120 rpm).

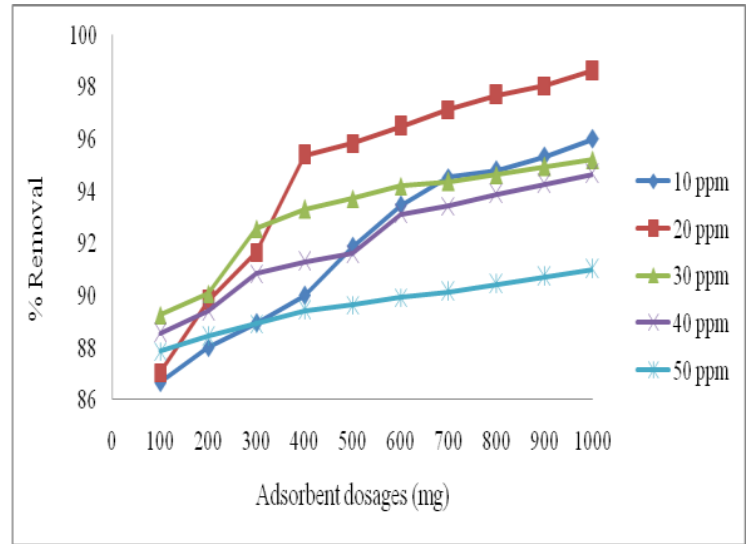

Figure 8:-Effect of adsorbent dosage on Malaghite Green adsorption on Activated carbon (Temperature - room temperature, $\mathrm{pH}$-solution $\mathrm{pH}$, speed-120 rpm).

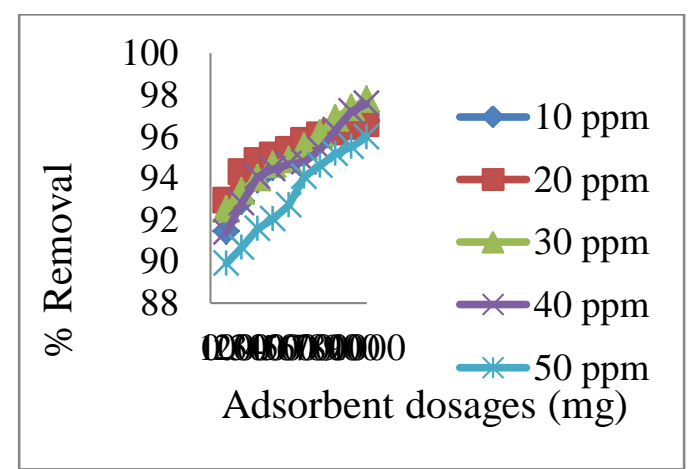

Figure 9:-Effect of adsorbent dosage on Methyl violet adsorption on Activated carbon (Temperature - room temperature, $\mathrm{pH}$-solution $\mathrm{pH}$, speed-120 rpm). 


\section{Effect of Temperature:-}

Temperature has a pronounced effect on the adsorption process from the change in temperature will cause changes in the equilibrium capacity of the adsorbent for adsorption of particular adsorbate. The percentage removal of methylene blue, malachite green and methyl violet has been studied at a temperature of $30^{\circ}, 40^{\circ}, 45^{\circ}, 50^{\circ}, 55^{\circ}$ and $60^{\circ} \mathrm{C}$ with initial concentration of $40 \mathrm{ppm}$. The percentage of three dyes (methylene blue, malachite green and methyl violet) removed at different temperature has been shown in figure 10 to 12 .

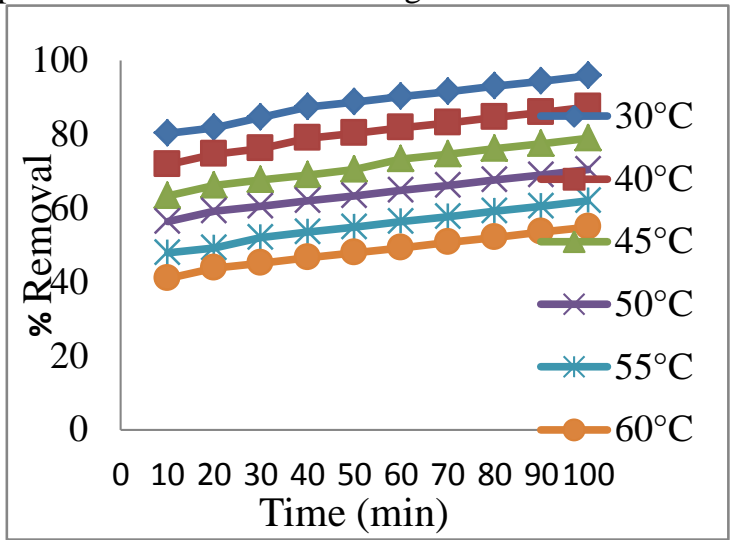

Figure10:-Effect of Temperature on Methylene Blue adsorption on Activated carbon (initial dye concentration - 4 $\mathrm{mg} / \mathrm{L}, \mathrm{pH}$-solution $\mathrm{pH}$, speed-120 rpm) and adsorbent dosage-100mg/50ml)

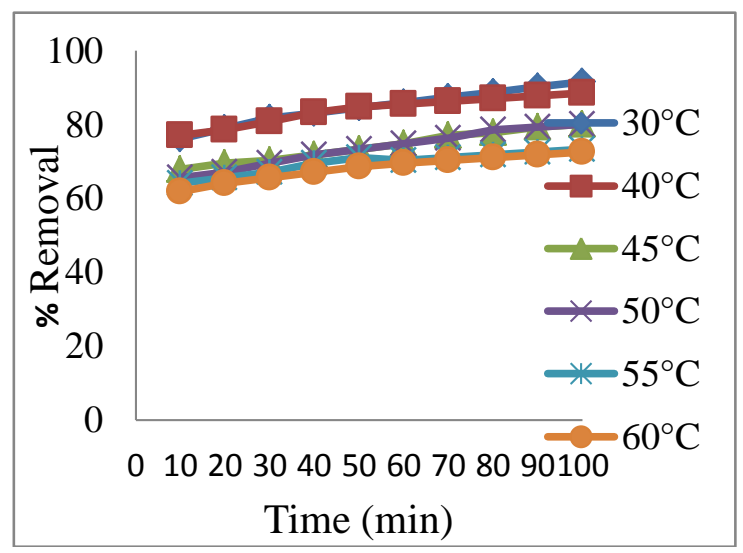

Figure 11:-Effect of Temperature on Malaghite green adsorption on Activated carbon (initial dye concentration - 40 $\mathrm{mg} / \mathrm{L}$, pH-solution $\mathrm{pH}$, speed-120 rpm) and adsorbent dosage-100mg/50ml)

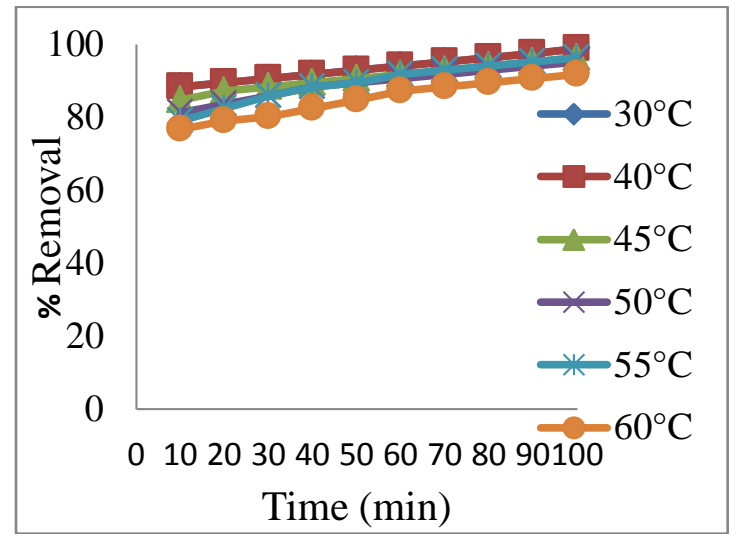

Figure 12:-Effect of Temperature on Methyl violet adsorption on Activated carbon (initial dye concentration - 40 $\mathrm{mg} / \mathrm{L}, \mathrm{pH}$-solution $\mathrm{pH}$, speed-120 rpm) and adsorbent dosage-100mg/50ml) 
In the present investigations it was observed that the adsorption capacity of activated carbon for the three dyes (methylene blue, malachite green and methyl violet) decreased with temperature. It is because higher temperature may decrease the adsorptive forces between the dye molecules and active sites on the adsorbent [16, 17]. The maximum percentage removal of dye was obtained at $30^{\circ} \mathrm{C}$. The uptake of dye decrease with the increase in temperature, indicating the exothermic nature of the adsorption reaction [18].

\section{Scanning Electron Microscope analysis:-}

The SEM photograph of the adsorbent is shown in figure.5. From the figure, it was observed that porous structure, cavities and rough surface morphology on the carbon. Pores developed on the surface of carbon increases active sites [19]. This active sites increased more number of dye adsorbed molecule on the surface of the carbon.

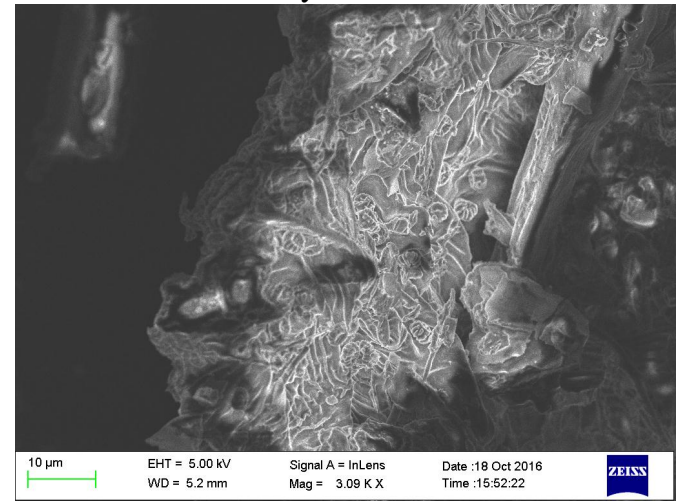

Fig.5:-SEM image of activated carbon.

\section{Powder X-ray diffraction study:-}

The powder X-ray diffraction analysis of sample investigated and displayed in Figure.6. In activated carbons, a broad peak due to reflections from the planes can be clearly seen. The broadness of the peak indicates the amorphous nature of the carbon sample [20].

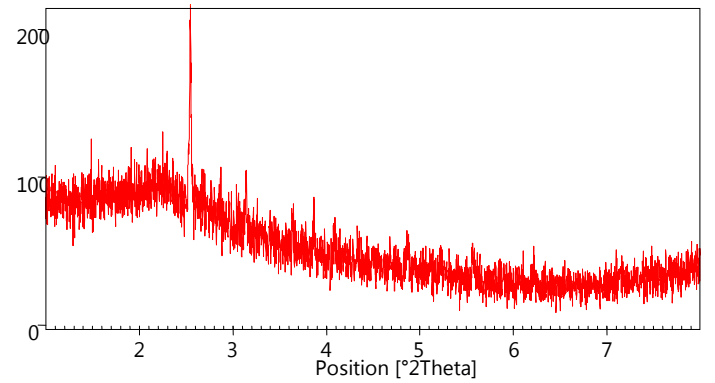

Fig.6. XRD pattern for prepared activated carbon

Figure.6.shows XRD spectrum of the adsorbent. This spectrum clearly shows that the particle size is responsible for the broadening peaks in the XRD pattern. This spectrum also indicates that the presence of amorphous form of carbon which is disorderly stacked up by carbon rings. It does not give any major peak which could be due to lack of inorganic compound in the adsorbent.

\section{Conclusion:-}

The removal of dyes (methylene blue, malachite green and methyl violet) from aqueous solutions by adsorption with activated carbon prepared from copper pod flower has been experimentally determined. The percentage of colour removed increase with increasing contact time, adsorbent dosage, temperature and varied with dye solution $\mathrm{pH}$. From the experimental results it was observed that the Optimum adsorbent dose for the dye is $1 \mathrm{~g}$. The percentage of colour removal increased with increasing adsorbent dose. This is due to increase in surface area and the number of free active sites of the adsorbent. The adsorption studies revealed that the optimum contact time required for equilibrium to be achieved was found to be nearly 100 minutes. The adsorption capacity of activated carbon for the three dyes (methylene blue, malachite green and methyl violet) increased with decreasing temperature from 30 to $60^{\circ} \mathrm{C}$ and initial dye concentration of $40 \mathrm{mg} / \mathrm{L}$ which indicates that exothermic nature of the adsorption process. 
Optimum temperature was found to be $30^{\circ} \mathrm{C}$ for the removal of $\mathrm{MB}$, MG and MV by copper pod flower. The percentage of colour removal of dyes (methylene blue, malachite green and methyl violet) increased with increasing $\mathrm{pH}$ from 2 to 7 . Maximum adsorption was found to be $\mathrm{pH}=7$. The SEM study also made support to it by observing difference in surface morphology of adsorbent. Finally it is concluded that, the present adsorbent could be a good alternative for the removal MB, MG and MV from aqueous solution very effectively and is inexpensive material.

\section{Acknowledgment:-}

The authors are thankful to the principal and the Head, Department of Chemistry, PSG College of Arts and Science, Coimbatore, Tamilnadu, India, for providing experiment facility and their guidance.

\section{Reference:-}

1. B.H. Hameed, A.T.M. Din, A.L. Ahmad Adsorption of methylene blue onto bamboo-based activated carbon:Kinetics and equilibrium studies, 2006.

2. C. Namasivayam*, D. Kavitha, Removal of Congo Red from water by adsorption onto activated carbon prepared from coir pith, an agricultural solid waste, Dyes and Pigments, vol.54 ,2002, pp.47-58.

3. A. Mittal, Adsorption kinetics of removal of a toxic dye, Malachite Green, from wastewater by using hen feathers. J. Hazard.Mater, vol.133, pp.196-202

4. I.A. Rahman, B. Saad, S. Shaidan, E.S. Sya Rizal, Adsorption characteristics of malachite green on activated carbon derived from rice husks produced by chemical-

5. thermal process, Bioresource Technology,vol. 96, 2005, pp.1578-1583.

6. K.Ranganathan,K.Karunagaran, D.C.Sharma, Recycling of wastewaters of textile dying industries using advances treatment technology and cost analysis - Case studies.Resources, conservation and recycling, vol.50, 2007, pp. $306-318$.

7. Y.Bulut and H., Audin" a kinetics and thermodynamics study of methylene blue adsorption on wheat shells" Desalination, vol. 194 , 2006, pp. 259 - 267.

8. V.K.Grag, Renuka Gupta., Anu Bala yadav., Rakesh Kumar, " Dye removal from aqueous solution by adsorption on treated sawdust". Bioresource Technology, vol.89(2), 2003, pp.121 - 124.

9. A. Mittal, D. Jhare, J. Mittal, Adsorption of hazardous dye Eosin Yellow from aqueous solution onto waste material De-oiled Soya: Isotherm, kinetics and bulk removal. J. Molecular Liquids. vol.179, 2013, pp. $133-140$.

10. Shaobin Wang., Boyjoo, Y., Choueib, a., Zhu, Z.H. "Removal of dyes from aqueous solution using fly ash and red mud". Water research, vol. 39(1), 2005, pp. 129 - 138.

11. Yamin Yasin, Mohd Zobir Hussein and Faujan Hj Ahmad, Adsorption of Methylene blue onto Treated Activated Carbon, The Malaysian Journal of Analytical Sciences, vol 11, No 11 ,2007, pp. 400 -406.

12. U Filipkowska, E. Klimiuk, S.Grabowski, E.Siedlecka, Adsorption of Reactive Dyes by Modified Chitin from Aqueous Solutions. Polish J.Environmental Studies, vol.11 (4), 2002, pp.315-323.

13. Grabowska Ewa Lorenc, Gryglewicz Gra_zyna, Adsorption characteristics of Congo Red on coal-based mesoporous activated carbon, Dyes and Pigments, vol. 74, 2007, pp. 34-40.

14. S.Mondal,"Methods of dye removal from dye house effluent an overview", Environmental Engineering Science, vol.25, 2008, pp. 383 - 396.

15. Indra Deo Mall, Vimal Chandra Srivastava, Nitin Kumar Agarwal, Indra Mani Mishra,adsorptive removal of malachite green dye from aqueous solution by bagasse fly ash and activated carbon kinetic study and equilibrium isotherm analysis. Colloids and surfaces, vol.264, 2005, pp.17-28.

16. G.Krishna, Bhattacharyya, Arunima Sharma, Kinetics and thermodynamics of Methylene Blue adsorption on Neem (Azadirachta indica) leaf powder. Dyes and Pigments, 65, 2005, pp. 51-59.

17. N. Emad, El Qada*, J. Stephen J. Allen, Gavin M. Walker, Adsorption of Methylene Blue onto activated carbon produced from steam activated bituminous coal, Chemical Engineering Journal, vol.124 ,2006, pp.103110 .

18. Nagarethinam Kannan and Mariappan Meenakshisundaram ,Adsorption of Congo red on Various Activated Carbons -A Comparative Study, 2001.

19. M. Hema and P. Martin Deva Prasath, Adsorption of malachite green onto carbon prepared from borassus bark, The Arabian Journal for Science and Engineering, vol. 34, Number 2A, July 2009.

20. R. A. Shawabkeh and E. S. M. Abu-Nameh Absorption of Phenol and Methylene Blue by Activated Carbon from Pecan Shells ISSN 1061-933X, Colloid Journal, 2007, vol. 69, No. 3, pp. 355-359.

21. C.Namasivayam, R. Radhika,S. Subha, " Uptake of dyes by a promising locally available agricultural solid waste: coir pith. "Waste Management, 21(4), 2001, pp.381 - 387. 